\title{
La grafología como recurso en el estudio y evaluacion de la personalidad
}

Graphology as a resource in the study and evaluation of personality

Hilda Blanco - Paredes a

\begin{abstract}
:
Graphology allows us to understand that the letter becomes the reflection of the individual's interior, thus allowing him to use it for the study and evaluation of the personality, identifying his thinking, his feeling and his actions of the individual, providing indicators of his family dynamics thus expressing their peronality unconsciously, so it is an objective way to have knowledge of the subject's actions in their different fields and without a doubt, an effective tool for the study and evaluation of the personality of the human being in the actuality for the understanding of their behavior.
\end{abstract}

Keywords:

Personality, character, temperament, graphology, behavioral evaluation, behavior.

\section{Resumen:}

La grafología nos permite entender, que la letra se convierte en el reflejo del interior del individuo, permitiendo asi hacer uso de esta para el estudio y evaluacion de la personalidad, identificando su pensar, su sentir y su actuar del individuo, brindando indicadores de su dinámica familiar expresando asi su peronalidad de modo inconsciente, por lo que es una manera objetiva de tener conocimiento del actuar del sujeto en sus diferentes ámbitos y sin duda alguna, una herramienta eficaz para el estudio y la evaluacion de la personalidad del ser humano en la actualidad para la comprensión de su comportamiento.

\section{Palabras Clave:}

Personalidad, carácter, temperamento, grafología, evaluacion comportamiento, conducta.

\section{Introducción}

Desde una perspectiva psicoanalítica La personalidad surge del conflicto entre nuestros impulsos instintivos tendientes a la agresividad y a la búsqueda de placer asi como de las limitaciones impuestas por una sociedad.

Por ello es de gran importancia el estudio de la misma considerando la intervencion de los diferentes procesos psicológicos y las diferencias individuales que surgen en cada sujeto, por lo que el definir, entender y comprender las características y rasgos de las personas, asi como su preceder en diferentes situaciones, se vuelve indispensable en el estudio de la personalidad de cada individuo. Desde diferentes planteamientos que abordan las posturas psicologicas, así cómo considerando el periodo histórico y las manifestaciones de conducta de los individuos.
Por lo que el estudio y evaluación de la personalidad es necesario a través de diversos recursos por mencionar algunos como, los test proyectivos, la grafología etc. siendo esta última el tema central de este artículo. Cabe señalar que la grafología no es una ciencia joven, a pesar de que en la actualidad se alla centrado la atención en ella en diferentes áreas, como la empresarial, donde es utilizada por los profesionales de recursos humanos por los beneficios que ofrece en virtud de las necesidades actuales en ese campo.

\section{Desarrollo}

De acuerdo con la grafología el ser humano es un "ser escriturado". Considerando que la escritura es la quinta esencia de la mujer y el hombre, siendo está, el acto de la voluntad de los reflejos condicionados Anatómica, fisiológica y psíquicamente, siendo influenciados desde 
luego por la educación, familia y sin lugar a duda la cultura.1

Por tanto el estudio de la escritura es el carácter del ser humano, a traves del cual se tiene acceso a los procesos inconscientes permitiendo de esta manera el estudio de la estructura psíquica, haciendo con ello una revisión de la construcción de la personalidad a partir de las proyecciones que realiza el sujeto, permitiendo no solo conocer rasgos de personalidad, sino además evaluar la misma.

Es asi como la grafología, como recurso en el estudio y evaluacion de la personalidad, trabaja con lo conciente e inconsciente del sujeto siendo esto observado en sus proyeccione. 2 Por lo que la escritura es el resultado de las funciones cerebrales. Reflejando la personalidad del sujeto considerando toda su complejidad.

Es preciso reiterar que la grafología es aplicable a varios campos de la psicología, área clínica, educativa laboral, entre otros, en menores y adultos, siempre nos dará datos importantes de la personalidad sujeto.

Por lo que abordar el estudio de la personalidad nos conlleva a mencionar los elementos de la misma. El temperamento y carácter, haciendo mayor énfasis en el primero.

No sin antes mencionar que la grafología es un diagnostico radiográfico de nuestra capacidad intelectual mediante el cual se pueden obtener características de personalidad y conocer el comportamiento del sujeto, desde distintas fases como; la agresividad, depresión o capacidad de entendimiento. Por ello es que la grafología se ha convertido en un recurso viable para el estudio preciso de la personalidad asi como para detectar lo psicosomático del sujeto.

De acuerdo con 2, quien cita a Mc Dougall quien define el temperamento como" una suma de efectos producidos sobre la propia vida psíquica por el metabolismo o cambios químicos que se efectúan constantemente en todos los tejidos del propio cuerpo.

Asi mismo 2, Plantea que Hipócrates y Galeno lo atribuían al predominio de los humores en el cuerpo.

También hay autores que dividen el temperamento y el carácter. Por lo que podemos entender que no hay un acuerdo total entre los diverso autores, ya sea cada autor o cada escuela se rige por su propia ideología o bien su punto de vista.

Es asi como Sigmund Freud en relación con su teoria psicosexual plantea el carácter en función del desarrollo de las etapas psicosexuales y como esté, interfiere en la formación de la personalidad.

De acuerdo con 2, Jung aborda la actitud vital y las funciones psíquicas mismas que ofrecen una clasificación mucho más matizada.Como podemos ver de acuerdo con varios autores se da con las tipologías que creemos más útiles desde el punto de vista grafológico.
Abordando la clasificación hipocrática que 2 retoma, acentuando la fisiología, endocrinología y la neurología, cada una de estas funciones condiciona según su predominio o jerarquía el tipo de temperamento y las tendencias, instintitos y necesidades de cada ser.

Entendiendo asi que la función nutritiva o digestiva determinara, los instintos, tendencias y necesidades peculiares de un sujeto con temperamento flemático.

El desarrollo de la función sexual estrechamente hermanada en el orden fisiológico con el aparato respiratorio y sanguíneo mismo que determinara las tendencias peculiares del temperamento sanguíneo.

De igual modo 2, plantea el predominio de la receptividad que como función se encarga de informarnos sobre nuestro mundo exterior registrando mediante la piel, las funciones mecánica, térmicas; mediante el ojo, las radiaciones electromagnéticas luminosas; por medio del oído, las vibraciones moleculares sonoras; mediante la mucosa nasal, los vapores químicos, etc., determinaría las tendencias privativas del temperamento nervioso.

Siendo asi como podemos explicar que la grafología es una herramienta a través de la cual obtenemos indicadores para la evaluacion de la personalidad. Considerando que existen tres niveles básicos del carácter o de la personalidad: la mente, las emociones y los instintitos es decir se plantea la capacidad de pensar, de sentir asi como de la conservación de sí mismo.

Es asi como se plantea el analisis grafológico En el cual es preciso hacer un reconocimiento general de los rasgos.

De acuerdo con 1, Es preciso observar el uso de los espacios, inclinaciones de las letras, direcciones, formas de letra, observar la precisión, poner énfasis en letras deformadas, correlacionar lo examinado con los tipos de temperamento para constatar el preponderante, asi mismo observar el orden que impera en el escrito, lo legible, limpieza y claridad. La forma, la proporción, la dimensión, inclinación, dirección de las líneas, la dirección de trazos, Orden, distribución y márgenes, así como la continuidad, la rapidez, la presión. Con la finalidad de analizar a detalle cada rasgo e indicador que permita en conjunto datos relevantes sobre el estudio y evaluación de la personalidad.

\section{Conclusión}

El desarrollo del sujeto permea la expresión de la personalidad, siendo el reflejo de esta la letra, los trazos. Exteriorizando a partir de la misma, emociones, sentimiento, pensamientos, valores e impulsos, siendo así como la grafología además de ser considera como parte de los test proyectivos importantes en el estudio y evaluacion de la personalidad, permite ser considerada como una herramienta valiosa debido a que los trazos son 
únicos y la escritura no miente por lo que en la actualidad es utilizada en diferentes campos de la psicología. Como lo empresarial, lo clínico, la psicoterapia, asi también en disciplinas como pedagogía, derecho, criminología, etc.

\section{Bibliografía}

[1]Emmaus, I., Aragón Chacón, L., \& Zapfe Medina, A. (2016). Grafologia. Una guía práctica. Cd. de Mexico: Trillas.

[2]Vels, A. (2010). Escritura y personalidad, las bases cientificas de la grafología. España: Herder. 